\title{
Association of Pregestational BMI and Gestational Weight Gain with Maternal and Neonatal Outcomes in Adolescents and Adults from Mexico City
}

Reyna Sámano ${ }^{1,2, * \mathbb{D}}$, Gabriela Chico-Barba ${ }^{1,3,4, * \mathbb{D}}$, María Eugenia Flores-Quijano ${ }^{1}$ (D), Estela Godínez-Martínez ${ }^{1}$ (D) Hugo Martínez-Rojano ${ }^{5}$ D , Luis Ortiz-Hernandez ${ }^{2,6}{ }^{\mathbb{D}}$, Oralia Nájera-Medina ${ }^{2,6}$, María Hernández-Trejo ${ }^{7}$ and Cristopher Hurtado-Solache ${ }^{8}$

check for

updates

Citation: Sámano, R.; Chico-Barba, G.; Flores-Quijano, M.E.; GodínezMartínez, E.; Martínez-Rojano, H.; Ortiz-Hernandez, L.; Nájera-Medina, O.; Hernández-Trejo, M.; Hurtado-

Solache, C. Association of

Pregestational BMI and Gestational Weight Gain with Maternal and Neonatal Outcomes in Adolescents and Adults from Mexico City. Int. J. Environ. Res. Public Health 2022, 19, 280. https://doi.org/10.3390/ ijerph19010280

Academic Editors: Madhulata Singh Chauhan and Yuanlin Dong

Received: 30 October 2021

Accepted: 24 December 2021

Published: 28 December 2021

Publisher's Note: MDPI stays neutral with regard to jurisdictional claims in published maps and institutional affiliations.

Copyright: (C) 2021 by the authors. Licensee MDPI, Basel, Switzerland. This article is an open access article distributed under the terms and conditions of the Creative Commons Attribution (CC BY) license (https:// creativecommons.org/licenses/by/ $4.0 /)$
1 Coordinación de Nutrición y Bioprogramación, Instituto Nacional de Perinatología, Secretaría de Salud, Mexico City 11000, Mexico; maru_fq@yahoo.com (M.E.F.-Q.); eygodinez@hotmail.com (E.G.-M.)

2 Programa de Posgrado Doctorado en Ciencias Biológicas y de la Salud, División de Ciencias Biológicas y de la Salud, Universidad Autónoma Metropolitana, Mexico City 04960, Mexico; lortiz@correo.xoc.uam.mx (L.O.-H.); onajera@correo.xoc.uam.mx (O.N.-M.)

3 Escuela de Enfermería, Facultad de Ciencias de la Salud, Universidad Panamericana, Mexico City 03920, Mexico

4 Programa de Maestría y Doctorado en Ciencias Médicas, Odontológicas y de la Salud, Universidad Nacional Autónoma de México, Mexico City 04510, Mexico

5 Sección de Posgrado e Investigación de la Escuela Superior de Medicina del Instituto Politécnico Nacional, Mexico City 11340, Mexico; hmartinez_59@yahoo.com.mx

6 Departamento de Atención a la Salud, Universidad Autónoma Metropolitana Xochimilco, Mexico City 04960, Mexico

7 Departamento de Neurobiología del Desarrollo, Instituto Nacional de Perinatología, Secretaría de Salud, Mexico City 11000, Mexico; maria.h.trejo72@gmail.com

8 Escuela de Ciencias de la Salud, Universidad del Valle de México-Chapultepec, Mexico City 11810, Mexico; cristopheralexis2324@hotmail.com

* Correspondence: ssmr0119@yahoo.com.mx (R.S.); gabyc3@gmail.com (G.C.-B.)

\begin{abstract}
During pregnancy, adolescents experience physiological changes different from adults because they have not concluded their physical growth. Therefore, maternal and neonatal outcomes may not be the same. This paper aimed to analyze the association between pregestational BMI (pBMI) and gestational weight gain (GWG) with maternal and neonatal outcomes in adolescent and adult pregnant women. The authors performed an observational study that included 1112 women, where $52.6 \%(n=585)$ were adolescents. Sociodemographic information, pBMI, GWG, neonatal anthropometric measures, and maternal and neonatal outcomes were obtained. Adolescent women had a mean lower (21.4 vs. 26.2, $p \leq 0.001)$ pBMI than adults and a higher gestational weight gain (12.3 vs. $10.7 \mathrm{~kg}, p \leq 0.001$ ). According to Poisson regression models, gestational diabetes is positively associated with insufficient GWG and with pregestational obesity. Furthermore, the probability of developing pregnancy-induced hypertension increased with pBMI of obesity compared to normal weight. Preeclampsia, anemia, and preterm birth were not associated with GWG. Insufficient GWG was a risk factor, and being overweight was a protective factor for low birth weight and small for gestational age. We conclude that pBMI, GWG, and age group were associated only with gestational diabetes and low birth weight.
\end{abstract}

Keywords: adolescent pregnancy; perinatal outcomes; preeclampsia; anemia; Mexico

\section{Introduction}

The Institute of Medicine (IOM) gestational weight gain guidelines recommend weight gain ranges for each pre-pregnancy body mass index (pBMI) category associated with a low prevalence of some maternal and neonatal adverse outcomes. These guidelines propose that adolescent pregnant women be categorized using BMI cutoff points for adults and be advised to gain within the same weight gain ranges [1]. Research has shown that some adolescents may stop or continue their physical growth during pregnancy [2], depending 
on their chronological age and energy stores [3,4]; this would also affect their perinatal outcomes [5]. The IOM recommendations take adolescent growth into account implicitly because lighter adolescents (possibly the younger ones) will most likely be categorized in the lower BMI group, and they would be recommended to gain weight at the highest range $[1,6]$.

Regarding the evidence of the effects of pBMI and GWG on maternal and neonatal outcomes, it has been reported that being underweight prior to pregnancy increases the risk for preterm birth and for delivering a small for gestational age (SGA) newborn. On the other hand, overweight and obesity are high-risk factors for gestational diabetes, hypertensive syndrome, and fetal growth disorders. Concerning weight gain, women with insufficient gestational weight gain may experience anemia. Conversely, those with excessive weight gain are at an elevated risk of cesarean delivery, preeclampsia, gestational diabetes, blood transfusions, weight retention after delivery, and long-term obesity [7].

In addition, excessive GWG has been associated with childhood and adolescent overweight and obesity [8].

Mexico is within the top three Latin American countries with the highest rate of adolescent pregnancy [9]; among the countries of the Organization for Economic Cooperation and Development (OECD), Mexico is first in the rank [10]. According to national data, almost one out of five pregnancies in Mexico is adolescent [11].

In studies with Mexican adolescent women, pregestational BMI has been different from adults $[5,12,13]$. Moreover, being a pregnant adolescent increases the risk of complications, including preeclampsia, preterm birth, and low infant birth weight [14].

Unfortunately, insufficient and excessive gestational weight gains occur in two-thirds of pregnant women in different world regions $[6,15,16]$. For example, excessive weight gain has been reported in 33-41\% of Mexican women, and inadequate gain in nearly 30\% [10,17].

Like adults, adolescents are likely to experience excessive gestational weight gain, and they would also have a risk of having neonatal and maternal adverse outcomes [18]. Nevertheless, knowledge about perinatal maternal and neonatal outcomes in this age group is inconsistent $[5,10,13,19]$. Thus, it is expected that neonatal outcomes would also differ. Therefore, this study aimed to analyze the association between pregestational BMI and gestational weight gain with maternal and neonatal outcomes in adolescent and adult pregnant women.

\section{Materials and Methods}

We performed a cross-sectional study at the Instituto Nacional de Perinatología (INPer) in Mexico City. The INPer is a National Institute of Health that provides antenatal care to uninsured, low-income women with high-risk pregnancies. Pregnant adolescents ( $\leq 19$ years old) and adult women (20-45 years old) were invited to participate in the study from 2013 to 2018. Sampling was non-probabilistic, and all consecutive women who met the following inclusion criteria were invited to participate: healthy singleton pregnancy, antenatal care and delivering her child in the INPer, and signed written informed consent. We excluded participants who consumed alcohol, tobacco, or drugs during pregnancy and those whose pregnancy resulted from rape. Participants were recruited during their outpatient consultation at the INPer.

\subsection{Sociodemographic and Clinical Data}

Age, educational level, occupation, and socioeconomic status were obtained through a questionnaire at the initial assessment. We obtained gestational age by ultrasound to define the trimester the participant initiated antenatal care at the INPer. Parity, history of disease, and type of delivery were obtained from clinical records.

\subsection{Anthropometric Evaluation}

Bodyweight was assessed at the beginning and the end of pregnancy. Pregestational weight was self-reported, and maximum gestational weight was obtained with a digital 
scale (TANITA, Tokyo, Japan, model BWB-800, accuracy $0.10 \mathrm{~kg}$ ) one week before delivering. In addition, trained personnel obtained height measurement at first visit using the Lohman technique [20] with a stadiometer (SECA, Hamburg, Germany, model 208, accuracy $0.1 \mathrm{~cm}$ ). pBMI was calculated using pregestational weight and the height from the first study visit. For adolescents, pBMI classification was obtained with AnthroPlus ${ }^{\circledR}$ (World Health Organization, Geneva, Switzerland) according to percentiles: underweight $<3 \mathrm{rd}$, normal weight 3-85th, overweight 85-97th, and obesity $\geq 97$ th [21]. Regarding adult women's pBMI classification, pBMI was categorized as follows: underweight $<18.5$, normal weight 18.5-24.99, overweight 25-29.99, obese $\geq 30$ [1].

\subsection{Gestational Weight Gain}

We got the total gestational weight gain through the maximum gestational weight minus pregestational weight in $\mathrm{kg}$. Then, according to the recommendations of the Institute of Medicine [22] of the United States of America, we classified the GWG based on each category of pBMI: underweight a gain of $12.5 \pm 18 \mathrm{~kg}$; normal weight a gain of $11.5 \pm 16 \mathrm{~kg}$; overweight a gain of $7 \pm 11.5 \mathrm{~kg}$; and obese a gain of $5 \pm 9 \mathrm{~kg}$. Then, GWG was divided into three categories: insufficient if the weight gain was below the recommendation; adequate if weight gain was within the recommendation; and excessive, when weight gain was above the recommendation.

\subsection{Maternal Outcomes}

Obstetricians registered pregnancy complications during prenatal visits to the INPer, and we obtained the information from the clinical records. Complications were identified and recorded in the following categories: gestational diabetes, pregnancy-induced hypertension, eclampsia/preeclampsia, and anemia.

According to medical procedures at the INPer, gestational diabetes was diagnosed between 24 and 28 gestational weeks by a glucose tolerance curve when one or more values were higher than expected-fasting glucose: $\geq 92 \mathrm{mg} / \mathrm{dL}$, and $180 \mathrm{mg} / \mathrm{dL}$ at one hour or $\geq 153$ at two hours, or $\geq 140 \mathrm{mg} / \mathrm{dL}$ at three hours, after a 75 g glucose charge. If the participants were diagnosed with diabetes before the week of gestation 24, they were considered as diabetes type 2 [23] and were excluded from the analysis. Pregnancy-induced hypertension was defined as systolic blood pressure $>140 \mathrm{~mm} / \mathrm{Hg}$ and diastolic blood pressure $>90 \mathrm{~mm} / \mathrm{Hg}[24,25]$. Preeclampsia was defined as the presence of new-onset hypertension and proteinuria occurring after 20 weeks gestation, whereas eclampsia was defined as the development of seizures in a woman with preeclampsia [25]. Anemia was classified when women had $<12.3 \mathrm{~g} / \mathrm{dL}$ during the second or/and third trimester; we used an altitude correction for hemoglobin of $+1.3 \mathrm{~g} / \mathrm{dL}$ [26].

\subsection{Neonatal Outcomes}

Gestational age was obtained by the Capurro method and recorded in weeks and days. If the gestational age was under 36.6 weeks, it was classified as preterm; the gestational age between $\geq 37$ and $\leq 42$ weeks was identified as a term delivery.

We measured and recorded weight (SECA 374, model "Baby and Mommy"; accuracy $0.1 \mathrm{~g}$ ) and length (stadiometer SECA 416; accuracy $0.1 \mathrm{~cm}$ ) at birth. Then, low birth weight (LBW) was defined as $<2500 \mathrm{~g}$ and small for gestational age (SGA) according to weight for gestational age of Mexican children [27].

\subsection{Ethical Aspects}

This research was approved by the Institutional Ethics, Biosafety, and Research Committees (registration numbers 212250-494811 and 2017-2-101). All adults, adolescents, and guardians were informed of the study's objectives and the procedures involved. Confidentiality was guaranteed by assigning a folio number during the participant's data collection and its analysis. 


\subsection{Statistical Analysis}

We performed univariate analysis to describe the sample characteristics. Categorical variables were presented as frequencies and percentages, and continuous variables as mean \pm standard deviation or median (p25-p75). We compared the frequencies of sociodemographic, maternal, and neonatal characteristics between adolescents and adults using the Chi-square test in the bivariate analysis. Unadjusted Poisson regression models were performed to analyze the association of GWG, age, pBMI as independent variables with maternal and neonatal outcomes as dependent variables. We ran three different models: in M1, the variables GWG and pBMI were introduced in different (independent) models; in M2, both variables, GWG and pBMI, were included in the same model as main effects; and in M3, both variables, GWG and pBMI, were included in the same model, with interaction with age.

All models were adjusted by socioeconomic level, initiation of prenatal care, parity, and history of diseases. The reference groups were adolescents, adequate GWG, and normal weight. Statistical significance was considered with a $p$-value $<0.050$. All analyses were performed using the software Stata/v.SE16.1 (College Station, TX, USA) [28].

\section{Results}

\subsection{Participants' Characteristics}

A total of 1112 pregnant women participated in the study, where $52.6 \%(n=585)$ of them were adolescents. The mean age for adolescents was $15.9 \pm 1.4$ years and $30.2 \pm 6.2$ years for adult participants. Table 1 shows that all sociodemographic and maternal characteristics were statistically different between age groups. Lower educational levels and being a student were more frequent among adolescents than in adults. Further, most adolescents initiated prenatal care in the second trimester, compared to adults who sought prenatal care in the first trimester. Pre-pregnancy BMI was lower in adolescents than adult mothers (21.4 vs. 26.2, $p \leq 0.001$ ). In contrast, the adolescent group had higher gestational weight gain than other participants (12.3 vs. $10.7 \mathrm{~kg}, p \leq 0.001)$. Pregestational overweight and obesity and excessive gestational weight gain were more common in pregnant adults than in adolescents. Gestational diabetes was more frequent within adult women than in adolescents. Overall, median hemoglobin was $14.00 \mathrm{~g} / \mathrm{dL}$; for adolescents it was $13.89 \mathrm{~g} / \mathrm{dL}$ and $14.1 \mathrm{~g} / \mathrm{dL}$ for adults $(p=0.003)$. However, the medians for both groups indicated a normal level of hemoglobin. Regarding the newborns, the mean birth weight was $2918 \pm 510 \mathrm{~g}$, and the median gestational age was 39 (min 26-max 40) weeks; (data not shown in table nor figures). Meanwhile, the percentage of preterm birth was higher in adult mothers $(p=0.035)$ Table 1 .

The GWG in categories was associated with pregestational BMI $(p<0.001)$, as seen in Figure 1. Excessive GWG was more frequent among women with overweight and obesity than in women with normal weight. Similar figures were observed when the association was stratified by the age group (data not shown).

\subsection{Maternal Outcomes}

Table 2 shows the Poisson regression models for gestational diabetes as the outcome variables. When GWG and pBMI were independently analyzed, we did not find any statistically significant association of the studied variables with gestational diabetes (M1). In Model 2, with main effects analysis, the probability of gestational diabetes was marginally observed ( $p=0.053$ ) for those with insufficient GWG. Factors associated with a likelihood of having gestational diabetes were having obesity (PR: 1.54, $p=0.038$ ) and being an adult (PR: $1.81, p=0.004)(\mathrm{M} 2)$. The interaction of GWG and age was statistically significant; the adults with insufficient weight gain had a 2.59 probability of having gestational diabetes than those with an adequate GWG.

Nevertheless, excessive GWG showed no association with gestational diabetes in adults. Likewise, no association with GWG was found in adolescents. Moreover, those participants with pregestational obesity had a 1.59 probability of gestational diabetes (M3). 
For the other maternal outcomes that we assessed, only the participants with obesity had a greater probability of pregnancy-induced hypertension than normal weight. We found no associations with preeclampsia nor anemia. Further, we did not observe any interaction between variables, as can be seen in Table 3.

\subsection{Neonatal Outcomes}

Regarding neonatal outcomes, Table 4 shows that neither age group, GWG, nor pBMI were associated with preterm birth; only being an adult showed a marginal association compared to adolescents (RP: $1.44, p=0.079$ ).

The factor that increased the probability of low birth weight was insufficient GWG (RP: 1.61, $p=0.008$ ). Contrarily, pregestational overweight marginally decreased the probability of having a low birth weight baby (M2).

Similar results were observed for the small for gestational age outcome. In M2, insufficient GWG marginally increased the probability of SGA (RP: $1.36, p=0.084$ ), but pregestational overweight decreased the probability (RP: $0.49, p=0.007$ ).

Table 1. Demographic and clinical characteristics of pregnant women and their newborns.

\begin{tabular}{|c|c|c|c|c|c|}
\hline & & Adolescents & Adults & Total & $p$-Value \\
\hline Variables & & $n(\%)$ & $n(\%)$ & $n(\%)$ & \\
\hline \multirow{13}{*}{ Sociodemographic } & Education level & & & & \multirow{5}{*}{$<0.001$} \\
\hline & Elementary school & $153(26.1)$ & $25(4.7)$ & $178(16.0)$ & \\
\hline & Junior high & $358(61.2)$ & $139(26.4)$ & $497(44.7)$ & \\
\hline & High school & $71(12.1)$ & $226(42.9)$ & $297(26.7)$ & \\
\hline & College & $3(0.5)$ & $137(26.0)$ & $140(12.6)$ & \\
\hline & Occupation & & & & \multirow{4}{*}{$<0.001$} \\
\hline & Homemaker & 465 (79.5) & $438(83.1)$ & $903(81.2)$ & \\
\hline & Student & $104(17.8)$ & $6(1.1)$ & $110(9.9)$ & \\
\hline & Employee & $16(2.7)$ & $83(15.8)$ & $99(8.9)$ & \\
\hline & Socioeconomic level & & & & \multirow{4}{*}{$<0.001$} \\
\hline & Low & 247 (42.2) & 409 (77.6) & $113(100)$ & \\
\hline & Middle & $237(40.5)$ & $106(20.1)$ & $343(100)$ & \\
\hline & High & $101(17.3)$ & $12(2.3)$ & $656(100)$ & \\
\hline \multirow{23}{*}{ Maternal } & Initiation of prenatal care & & & & \multirow{4}{*}{$<0.001$} \\
\hline & 1st trimester & $193(33.0)$ & $284(53.9)$ & 477 (42.9) & \\
\hline & 2nd trimester & $328(56.1)$ & $196(37.2)$ & $524(47.1)$ & \\
\hline & 3rd trimester & $64(10.9)$ & $47(8.9)$ & $111(10.0)$ & \\
\hline & Pre-pregnancy BMI & & & & \multirow{3}{*}{$<0.001$} \\
\hline & Underweight & $29(5.0)$ & $20(3.8)$ & $49(4.4)$ & \\
\hline & Normal weight & $430(73.5)$ & $230(43.6)$ & $660(59.4)$ & \\
\hline & Overweight & $67(11.5)$ & $156(29.6)$ & $223(20.1)$ & \multirow{6}{*}{0.022} \\
\hline & Obesity & $59(10.1)$ & $121(23.0)$ & $180(16.2)$ & \\
\hline & Gestational weight gain & & & & \\
\hline & Insufficient & $214(36.6)$ & $211(40.0)$ & $425(38.2)$ & \\
\hline & Adequate & $207(35.4)$ & $146(27.7)$ & $353(31.7)$ & \\
\hline & Excessive & $164(28.0)$ & $170(32.3)$ & $334(30.0)$ & \\
\hline & Parity & & & & \\
\hline & Primigravida & $521(89.1)$ & $271(51.4)$ & $792(71.2)$ & \multirow[t]{2}{*}{$<0.001$} \\
\hline & Multigesta & $64(10.9)$ & $256(48.6)$ & $320(28.8)$ & \\
\hline & Cesarean section & $272(46.5)$ & $367(69.9)$ & $639(57.6)$ & $<0.001$ \\
\hline & History of disease & $137(23.4)$ & $192(36.4)$ & $329(29.6)$ & $<0.001$ \\
\hline & $\begin{array}{l}\text { Complications during } \\
\text { pregnancy }\end{array}$ & & & & \\
\hline & Gestational diabetes & $53(9.1)$ & $111(21.1)$ & $164(14.7)$ & $<0.001$ \\
\hline & Preeclampsia & $34(5.8)$ & $31(5.9)$ & $65(5.8)$ & 0.960 \\
\hline & $\begin{array}{l}\text { Pregnancy-induced } \\
\text { hypertension }\end{array}$ & $54(9.2)$ & $48(9.1)$ & $102(9.2)$ & 0.944 \\
\hline & Anemia ${ }^{1}$ & $44(9.4)$ & $59(11.5)$ & $103(10.5)$ & 0.274 \\
\hline \multirow{5}{*}{ Neonate } & Preterm & $61(10.4)$ & $77(14.6)$ & $138(12.4)$ & 0.035 \\
\hline & Low birth weight & $94(16.1)$ & $87(16.5)$ & $181(16.3)$ & 0.843 \\
\hline & Small for gestational age & $102(17.4)$ & $72(13.7)$ & $174(15.6)$ & 0.084 \\
\hline & Macrosomia & $3(0.5)$ & $11(2.1)$ & $14(1.3)$ & 0.019 \\
\hline & Large for gestational age & $15(2.6)$ & $27(5.1)$ & $42(3.8)$ & 0.025 \\
\hline
\end{tabular}




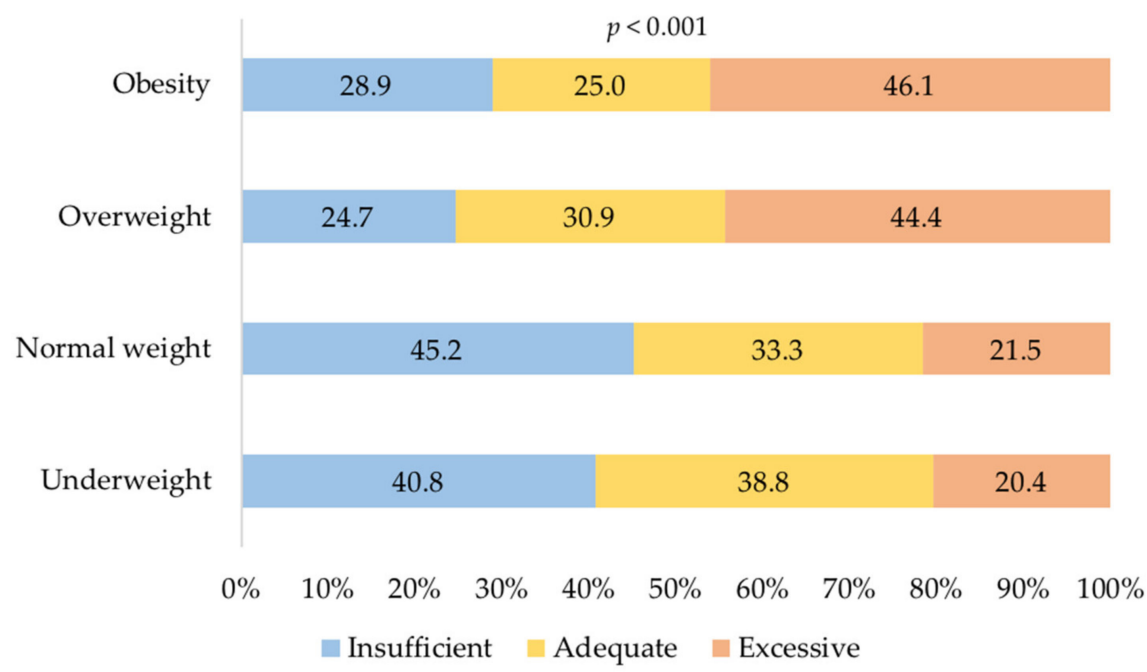

Figure 1. Gestational weight gain by pregestational body mass index.

Table 2. Poisson regression models for the association of GWG and pBMI with gestational diabetes as the outcome variable.

\begin{tabular}{|c|c|c|c|c|c|c|}
\hline \multirow[b]{2}{*}{ Variable } & \multicolumn{2}{|c|}{ M1 } & \multicolumn{2}{|c|}{ M2 } & \multicolumn{2}{|c|}{ M3 } \\
\hline & PR & $p$-Value & PR & $p$-Value & PR & $p$-Value \\
\hline \multicolumn{7}{|l|}{ Age group } \\
\hline Adults & - & - & 1.81 & 0.004 & 1.06 & 0.862 \\
\hline \multicolumn{7}{|l|}{ GWG } \\
\hline Insufficient & 1.41 & 0.080 & 1.46 & 0.053 & 0.80 & 0.490 \\
\hline Excessive & 1.22 & 0.344 & 1.13 & 0.574 & 0.83 & 0.592 \\
\hline \multicolumn{7}{|c|}{ Interaction of GWG with age } \\
\hline Insufficient & - & - & - & - & 2.59 & 0.023 \\
\hline Excessive & - & - & - & - & 1.67 & 0.239 \\
\hline \multicolumn{7}{|l|}{ pBMI } \\
\hline Underweight & 0.70 & 0.489 & 0.71 & 0.503 & 0.71 & 0.514 \\
\hline Overweight & 1.21 & 0.342 & 1.29 & 0.218 & 1.30 & 0.196 \\
\hline Obesity & 1.45 & 0.065 & 1.54 & 0.038 & 1.59 & 0.028 \\
\hline
\end{tabular}

GWG: Gestational Weight Gain, pBMI: pregestational body mass index, M1: model 1, M2: model 2, M3: model 3, PR: prevalence ratio. In M1, the variables GWG and pBMI were introduced in different (independent) models. In M2, both variables, GWG and pBMI, were included in the same model as main effects. In M3, both variables, GWG and pBMI, were included in the same model, with interaction with age. All models were adjusted by socioeconomic level, initiation of prenatal care, parity, and history of diseases. The reference groups were adolescents, adequate GWG, and normal weight.

Table 3. Poisson regression models for the association of GWG and pBMI with preeclampsia, pregnancy-induced hypertension, and anemia.

\begin{tabular}{ccccc}
\hline & \multicolumn{2}{c}{ M1 } & \multicolumn{2}{c}{ M2 } \\
\hline Variable & PR & $p$-Value & PR & $p$-Value \\
\hline Preeclampsia & & & & \\
Age group & & & 0.82 & 0.500 \\
Adults & - & & & \\
GWG & & & 0.68 & 0.217 \\
Insufficient & 0.68 & 0.225 & 0.98 & 0.948 \\
Excessive & 1.06 & 0.839 & & \\
pBMI & & & 0.00 & 0.981 \\
Underweight & 0.00 & 0.981 & 0.92 & 0.818 \\
Overweight & 1.00 & 0.993 & 1.58 & 0.153 \\
Obesity & 1.68 & 0.095 & &
\end{tabular}


Table 3. Cont.

\begin{tabular}{|c|c|c|c|c|}
\hline \multirow[b]{2}{*}{ Variable } & \multicolumn{2}{|c|}{ M1 } & \multicolumn{2}{|c|}{ M2 } \\
\hline & PR & $p$-Value & PR & $p$-Value \\
\hline \multicolumn{5}{|c|}{$\begin{array}{l}\text { Pregnancy-induced } \\
\text { hypertension }\end{array}$} \\
\hline \multicolumn{5}{|l|}{ Age group } \\
\hline \multicolumn{4}{|l|}{ GWG } & 0.092 \\
\hline Insufficient & 0.73 & 0.219 & 0.74 & 0.239 \\
\hline $\begin{array}{l}\text { Excessive } \\
\text { pBMI }\end{array}$ & 1.20 & 0.449 & 1.09 & 0.718 \\
\hline Underweight & 0.23 & 0.142 & 0.23 & 0.140 \\
\hline Overweight & 1.17 & 0.564 & 1.07 & 0.796 \\
\hline Obesity & 1.84 & 0.015 & 1.70 & 0.039 \\
\hline \multicolumn{5}{|l|}{ Anemia } \\
\hline $\begin{array}{l}\text { Adults } \\
\text { GWG }\end{array}$ & - & - & 1.10 & 0.698 \\
\hline Insufficient & 0.98 & 0.938 & 0.96 & 0.855 \\
\hline $\begin{array}{l}\text { Excessive } \\
\text { pBMI }\end{array}$ & 0.70 & 0.178 & 0.76 & 0.296 \\
\hline Underweight & 1.87 & 0.082 & 1.86 & 0.086 \\
\hline Overweight & 0.78 & 0.359 & 0.82 & 0.465 \\
\hline Obesity & 0.65 & 0.168 & 0.69 & 0.249 \\
\hline
\end{tabular}

GWG: Gestational Weight Gain, pBMI: pregestational body mass index, M1: model 1, M2: model 2, PR: prevalence ratio. In M1, the variables GWG and pBMI were introduced in different (independent) models. In M2, both variables, GWG and pBMI, were included in the same model as the main effects. All models were adjusted by socioeconomic level, initiation of prenatal care, parity, and history of diseases. The reference groups were adolescents, adequate GWG, and normal weight.

Table 4. Poisson regression models for the association of GWG and pBMI with preterm birth, small for gestational age and low birth weight.

\begin{tabular}{|c|c|c|c|c|}
\hline \multirow[b]{2}{*}{ Variable } & \multicolumn{2}{|c|}{ M1 } & \multicolumn{2}{|c|}{ M2 } \\
\hline & PR & $p$-Value & PR & $p$-Value \\
\hline \multicolumn{5}{|l|}{ Preterm } \\
\hline \multicolumn{5}{|l|}{ Age group } \\
\hline Adults & - & - & 1.44 & 0.079 \\
\hline \multicolumn{5}{|l|}{ GWG } \\
\hline Insufficient & 1.35 & 0.141 & 1.33 & 0.157 \\
\hline $\begin{array}{c}\text { Excessive } \\
\text { pBMI }\end{array}$ & 0.82 & 0.401 & 0.83 & 0.430 \\
\hline Underweight & 0.99 & 0.972 & 0.99 & 0.987 \\
\hline Overweight & 0.80 & 0.343 & 0.90 & 0.661 \\
\hline Obesity & 0.88 & 0.615 & 0.98 & 0.951 \\
\hline \multicolumn{5}{|l|}{$\begin{array}{l}\text { Low birth } \\
\text { weight }\end{array}$} \\
\hline \multicolumn{5}{|l|}{ Age group } \\
\hline $\begin{array}{l}\text { Adults } \\
\text { GWG }\end{array}$ & - & - & 1.11 & 0.579 \\
\hline Insufficient & 1.67 & 0.004 & 1.61 & 0.008 \\
\hline $\begin{array}{c}\text { Excessive } \\
\text { pBMI }\end{array}$ & 0.91 & 0.679 & 0.97 & 0.906 \\
\hline Underweight & 0.85 & 0.665 & 0.87 & 0.704 \\
\hline Overweight & 0.58 & 0.015 & 0.66 & 0.066 \\
\hline Obesity & 0.66 & 0.071 & 0.73 & 0.177 \\
\hline
\end{tabular}


Table 4. Cont.

\begin{tabular}{ccccc}
\hline & \multicolumn{2}{c}{ M1 } & \multicolumn{2}{c}{ M2 } \\
\hline Variable & PR & $p$-Value & PR & $p$-Value \\
\hline Small for & & & & \\
gestational age & & & 0.82 & 0.305 \\
Age group & - & & \\
$\quad$ Adults & & & 1.36 & 0.084 \\
$\quad$ GWG & 1.43 & 0.046 & 0.92 & 0.704 \\
Insufficient & 0.84 & 0.429 & & \\
Excessive & & & 1.19 & 0.579 \\
$\quad$ pBMI & 1.18 & 0.609 & 0.49 & 0.007 \\
Underweight & 0.44 & 0.002 & 0.77 & 0.284 \\
Overweight & 0.72 & 0.155 & & \\
$\quad$ Obesity & & & &
\end{tabular}

GWG: Gestational Weight Gain, pBMI: pregestational body mass index, M1: model 1, M2: model 2, M3: model 3, PR: prevalence ratio. In M1, the variables GWG and pBMI were introduced in different (independent) models. In M2, both variables, GWG and pBMI, were included in the same model as main effects. All models were adjusted by socioeconomic level, initiation of antenatal care, parity, and history of diseases. The reference groups were adolescents, adequate GWG, and normal weight.

\section{Discussion}

This investigation identified that GWG and age are risk factors for maternal and neonatal outcomes. Our study highlights that insufficient GWG and pre-pregnancy BMI were associated with gestational diabetes mellitus. Contrary to expectations, the adult women group was associated with gestational diabetes but not with preeclampsia.

In our study, more adolescent women started pregnancy with an adequate BMI while more adult women had pregestational overweight or obesity. By the end of gestation, the younger group had a higher GWG in $\mathrm{kg}$ compared to adults, as had been previously observed in other hospital-based studies with Mexican and Chinese women [5,29]. These observations are consistent with the IOM presumption that adolescents, especially the younger ones, would more likely be categorized in a "lighter group" and thus be advised to gain more weight [1,29].

Three out of ten participants had adequate GWG, which was more frequent among adolescent women than adults; this information was similar to a US study [30]. In contrast, other publications did not observe differences in the distribution of GWG categories between age groups [31]. Variations in the percentages of GWG categories in the different studies may be due to the availability of antenatal care and ethnic and racial differences, ranging from $50 \%$ to $61 \%$ for excessive GWG and from $20 \%$ to $30 \%$ for adequate [29].

Our results showed that the cesarean-section rate was higher than the recommended by the WHO [32]. The Latin American region has the highest rates of cesarean section worldwide [5,33]. C-section increases healthcare costs and negatively affects exclusive breastfeeding [34].

\subsection{Maternal Outcomes}

Unlike other studies $[19,35,36]$, our research showed that the frequency of anemia was similar among adolescents and adults. Nevertheless, our results agree with a study performed with Mexican women [5]. Regarding anemia, we only have a marginal statistically significant association with pregestational low weight. However, in other studies, pregestational low weight has been associated with an increased risk of anemia [37,38]. Therefore, it could be pertinent to highlight the concern and importance of timely antenatal care, especially in adolescent women.

\subsubsection{Gestational Diabetes}

Our study showed a higher frequency of gestational diabetes in adults and even in adolescent women, compared to data from Mexican studies [5,39], where the prevalence 
ranged from $1 \%$ to $3.4 \%$ compared with the $14.5 \%$ from our research. The discrepancy may be explained since our study took place at a tertiary care center, where complicated pregnancies are referred.

We found that among the adult participants, pregestational obesity was associated with a higher risk of gestational diabetes. However, in adolescent women, this relationship was not observed. Our findings highlighted that gestational diabetes was higher among adult women who started pregnancy with pregestational obesity and adults with insufficient GWG. These findings coincide with other research showing that insufficient GWG among women with prior diabetes and gestational diabetes is up to $50 \%$, and excessive GWG is 20\% in Hispanics [40] and Anglo-Saxon women [41]. An explanation for the insufficient GWG is that women diagnosed with gestational diabetes in weeks 24-28 are likely to change their habits, and less gestational weight gain is recommended after diagnosis [42] In this sense, a healthy lifestyle is encouraged for pregnant women, and GWG is timely monitored, resulting in insufficient weight gain [43]. According to the IOM, in first-level care hospitals, personalized attention is offered focused on the care women should have to avoid complications, resulting in insufficient GWG in the overweight and obese women [44]. In the INPer, almost all women are diagnosed in the 24-28 weeks of gestation and have personalized antenatal care, which coincides with previous statements.

\subsubsection{Preeclampsia}

Preeclampsia is a disease that is more common in adolescents than in adult women, and it has a high maternal-fetal mortality rate [45]. However, the rate of preeclampsia in our study (5\%) was similar in both age groups (adolescents vs. adults), but it was higher than the reported in a multicentric study [35], in specialized care [46] or tertiary care centers [45]. None of the risk factors that we assessed in our study were associated with preeclampsia, possibly because of other risk factors [47] that we did not take into account in our study, such as the maternal family history of preeclampsia, polymorphisms, or nutrition-related factors previously associated with this complication [48].

Our results show that none of the models' independent or adjusting variables, such as the initiation of timely antenatal care, were associated with pregnancy-induced hypertension. According to the evidence, the initiation of timely antenatal care prevents different pregnancy complications [45], which may be risk factors for preeclampsia [49].

Pregestational obesity increased the probability of pregnancy-induced hypertension, similar to findings from other studies [50,51]. This association may be explained by the link with the secretion of proinflammatory cytokines that are associated with adverse events [51].

\subsubsection{Anemia}

Anemia frequency was similar in adolescent and adult women in our study. We found a marginal association of anemia with low weight pBMI $(p=0.086)$, but maternal age and GWG were not associated. In white women from the USA, pre-pregnancy obesity was not associated with anemia. Anemia was less frequent in women with obesity than normal weight; the authors conclude that the excess weight can sequester iron of the stores [52]. Regarding GWG in a study performed with Brazilians, although 30\% was supplemented with iron and folic acid, their prevalence of anemia was 17\%. Furthermore, they did not find any association between inadequate GWG (excessive or insufficient) and anemia [53]. In Mexico, supplementation of iron in either of the schemes daily or weekly has effectively prevented anemia among pregnant women and low birth weight in their neonates [54].

According to data obtained from the INPer patients, anemia in pregnant adolescents has decreased from $80 \%$ in 2003 [55] to 38\% in 2012 [56]. Our results show even a lower frequency of $10 \%$. In Mexico, according to the national health norm NOM-007 [57], all pregnant women should receive prophylactic and therapeutic iron supplementation from the second trimester of gestation. Although we did not evaluate compliance with supplementation recommendations, we may infer that this maneuver could have resulted in the 
low percentage of anemia found in our study. If this is correct, we could document that antenatal care in this institutional environment would effectively prevent some adverse perinatal outcomes due to the low frequency of anemia in our sample. On the other hand, a third of the pregnancies have low pregestational weight and anemia; this combination is associated with adverse perinatal outcomes [58].

\subsection{Neonatal Outcomes}

Our data showed that adolescent and adult mothers had 10.4\% and $14.0 \%$ of preterm neonates, respectively. Other multi-country studies reported different results than ours [35,59], where the higher figures among those $<15$ years old were nearing $7 \%$, which was lower than our results. In Japan, preterm prevalence was not different between adolescents and adults, although the prevalence reached 20\% [60]. The discrepancies in the frequency of preterm birth may be explained by socio-cultural context and the quality of antenatal care from each region.

A multicentric study showed that younger adolescents had a higher prevalence of low birth weight [35]. Nevertheless, in our study adolescents and adults had similar frequencies of low birth weight neonates, although the Poisson regression models showed that adults with insufficient GWG have a higher probability of low birth weight. However, there was a marginal association. Similar data were found in other studies [58,59], highlighting other associated factors such as age and pBMI [61].

Adolescents in our study had a higher frequency of small for gestational age babies compared to adult mothers, these data coincide with other research $[5,59]$. The authors highlight their concern of inadequate antenatal care as a possible explanation [5]. Women under 19 years frequently initiate care later than adults [62], which delays and limits professional advice to prevent pregnancy complications. Another factor associated with small-forgestational-age during adolescence is the competence for nutrients between adolescents and their fetuses [63].

Regarding pregestational overweight as a protective factor to small-for-gestationalage neonates, previous research has directly related pBMI and intrauterine growth [64]. However, women with pre-pregnancy excess weight are more prone to have macrosomic or large-for-gestational-age babies [65-67], which is more common among adult women. In addition, adults with high pBMI have a higher risk of gestational diabetes mellitus, resulting in more adverse neonatal outcomes [68]. The above argument could explain pregestational overweight as a protective factor for small-for-gestational-age babies in our study. On the other hand, we had a few large-for-gestational-age and macrosomia neonate cases. Maybe, for this reason, these variables were not significant in the different models.

\subsection{Limitations and Strengths}

Our research has some limitations. We did not assess sociodemographic, clinical, and mental health (depression, network support during pregnancy) characteristics that may play a role in the perinatal outcomes. Further, our sampling was consecutive and convenient; therefore, our results cannot be generalized to all Mexican pregnant women. Nevertheless, our results open the line to other research exploring other variables in a more representative sample that compares among more than two age groups (e.g., >35 age pregnant women). On the other hand, we did not have the cesarean-section delivery election reasons, whose frequency was high in our sample. Another limitation is that we used self-reported pre-pregnancy weight which could introduce bias; however, evidence supports the use of self-reported weight as a cost-effective and practical measurement [69].

One strength of our study was the similar number of adolescents and adult women and a wide range of ages, which allowed us to have a more complex context of the maternal and neonatal outcomes of a sample of women from a tertiary care center. Besides this, in the adolescent group, we classified pBMI according to parameters suitable for their age. Thus, our research updates this topic from a developing country with a high rate of teenage pregnancy, overweight, and obesity in the female population. Although there is much 
evidence regarding pBMI, GWG, and perinatal outcomes, another strength of our study is that we found that gestational diabetes is also high in pregnant adolescents, which we did not expect. In this sense, timely interventions are needed in this age group because pregnancy impacts the adolescents' growth [4] and is probably determining their future metabolic health and their offspring's. Moreover, teenage mothers usually get pregnant later on, and having had gestational diabetes makes them prone to more maternal and neonatal complications.

\title{
5. Conclusions
}

In a sample of pregnant Mexicans who received antenatal care at a tertiary care center, pregestational BMI was associated with gestational diabetes and pregnancy-induced hypertension. An insufficient GWG and being an adult woman were associated with the probability of gestational diabetes and, marginally, with anemia.

This study was carried out in a tertiary hospital, where pregnant women with a higher risk of complications and adverse perinatal outcomes, such as adolescents or starting pregnancy with low or high BMI, are treated. Therefore, it was important to describe how a modifiable factor, such as gestational weight gain, modifies the risk of such adverse outcomes.

The study results confirm the need to create environments and promote strategies that prevent adolescent pregnancy and promote lifestyles that help women of reproductive age start pregnancy with adequate and healthy weight and provide the necessary advice and support to promote adequate weight gain.

Author Contributions: Conceptualization, R.S. and G.C.-B.; Data curation, G.C.-B., M.E.F.-Q., H.M.-R. and O.N.-M.; Formal analysis, R.S., G.C.-B. and L.O.-H.; Funding acquisition, R.S.; Investigation, M.E.F.-Q., E.G.-M., H.M.-R., L.O.-H., O.N.-M., M.H.-T. and C.H.-S.; Methodology, R.S.; Project administration, R.S. and G.C.-B.; Supervision, R.S. and G.C.-B.; Writing-original draft preparation, R.S. and G.C.-B.; Writing—review and editing, R.S., G.C.-B., M.E.F.-Q., E.G.-M., H.M.-R., L.O.-H., O.N.-M., M.H.-T. and C.H.-S. All authors have read and agreed to the published version of the manuscript.

Funding: This study was funded by the Instituto Nacional de Perinatología (registration numbers 2017-2-101 and 212250-494811) and by CONACyT (Registration number A3-S-40575).

Institutional Review Board Statement: The study was approved by the Institute National of Perinatology Ethics Committee (registration number 212250-494811 in February 2014; and 2017-2-101 on 10 April 2019) according to the basic principles of the Declaration of Helsinki.

Informed Consent Statement: Informed consent was obtained from all subjects involved in the study.

Data Availability Statement: The data presented in this study are available from the corresponding author upon reasonable request.

Acknowledgments: We extend profound thanks to all adolescent pregnant women and their parents/guardians, and adult women for their participation and cooperation in this study.

Conflicts of Interest: The authors declare no conflict of interest.

\author{
Abbreviations \\ GWG Gestational weight gain \\ BMI Body mass index \\ pBMI Pregestational body mass index \\ IOM Institute of Medicine \\ INPer National Institute of Perinatology \\ USA United States of America \\ WHO World Health Organization
}




\section{References}

1. Institute of Medicine (US) and National Research Council (US) Committee to Reexamine IOM Pregnancy Weight Guidelines. Weight Gain during Pregnancy: Reexamining the Guidelines; The National Academies Collection: Reports Funded by National Institutes of Health; Rasmussen, K.M., Yaktine, A.L., Eds.; National Academies Press: Washington, DC, USA, 2009; ISBN 9780309131131.

2. Scholl, T.O.; Stein, T.P.; Smith, W.K. Leptin and maternal growth during adolescent pregnancy. Am. J. Clin. Nutr. 2000, 72, 1542-1547. [CrossRef] [PubMed]

3. Scholl, T.O.; Hediger, M.L.; Schall, J.I.; Khoo, C.S.; Fischer, R.L. Maternal growth during pregnancy and the competition for nutrients. Am. J. Clin. Nutr. 1994, 60, 183-188. [CrossRef] [PubMed]

4. Sámano, R.; Martínez-Rojano, H.; Chico-Barba, G.; Hernández-Trejo, M.; Guzmán, R.; Arteaga-Troncoso, G.; Figueroa-Pérez, M.A.; Morales, R.M.; Martínez, G. Associations between prenatal serum levels of leptin, IGF-I, and estradiol and adolescent mothers' height gain during and after pregnancy. PLOS ONE 2020, 15, e0228706. [CrossRef] [PubMed]

5. Minjares-Granillo, R.O.; Reza-López, S.A.; Caballero-Valdez, S.; Levario-Carrillo, M.; Chávez-Corral, D.V. Maternal and Perinatal Outcomes Among Adolescents and Mature Women: A Hospital-Based Study in the North of Mexico. J. Pediatr. Adolesc. Gynecol. 2016, 29, 304-311. [CrossRef]

6. Rogozińska, E.; Zamora, J.; Marlin, N.; Betrán, A.P.; Astrup, A.; Bogaerts, A.; Cecatti, J.G.; Dodd, J.M.; Facchinetti, F.; Geiker, N.R.W.; et al. Gestational weight gain outside the Institute of Medicine recommendations and adverse pregnancy outcomes: Analysis using individual participant data from randomised trials. BMC Pregnancy Childbirth 2019, 19, 322. [CrossRef]

7. Sun, Y.; Shen, Z.; Zhan, Y.; Wang, Y.; Ma, S.; Zhang, S.; Liu, J.; Wu, S.; Feng, Y.; Chen, Y.; et al. Effects of pre-pregnancy body mass index and gestational weight gain on maternal and infant complications. BMC Pregnancy Childbirth 2020, 20, 390. [CrossRef]

8. Elwan, D.; Olveda, R.; Medrano, R.; Wojcicki, J.M. Excess Pregnancy Weight Gain in Latinas: Impact on Infant's Adiposity and Growth Hormones at Birth. Prev. Med. Rep. 2021, 22, 101341. [CrossRef]

9. United Nations World Population Prospects-Population Division. Available online: https://population.un.org/wpp/Download/ Standard/Fertility/ (accessed on 10 December 2021).

10. OECD. The World Bank Health at a Glance: Latin America and the Caribbean 2020; OECD Publishing: Paris, France, 2020.

11. INEGI Natalidad y Fecundidad. Available online: https:/ / www.inegi.org.mx/temas/natalidad/ (accessed on 10 December 2021).

12. Perichart-Perera, O.; Muñoz-Manrique, C.; Reyes-López, A.; Tolentino-Dolores, M.; Sosa, S.E.Y.; Ramírez-González, M.C. Metabolic markers during pregnancy and their association with maternal and newborn weight status. PLoS ONE 2017, 12, e0180874. [CrossRef]

13. Sámano, R.S.; Casanueva, E.; Vergara, A.; Pizano-Zárate, M.L.; Jiménez, D.; Godínez, E. Adolescents increase to more gestational weight and fat than adults according to BMI pre-gestational. Rev. Investig. Clin. 2011, 63, 500-508.

14. Marvin-Dowle, K.; Soltani, H. A comparison of neonatal outcomes between adolescent and adult mothers in de-veloped countries: A systematic review and meta-analysis. Eur. J. Obstet. Gynecol. Reprod. Biol. X 2020, 6, 100109. [CrossRef]

15. Ukah, U.V.; Vivian Ukah, U.; Bayrampour, H.; Sabr, Y.; Razaz, N.; Chan, W.-S.; Lim, K.I.; Lisonkova, S. Association between Gestational Weight Gain and Severe Adverse Birth Outcomes in Washington State, US: A Population-Based Retrospective Cohort Study, 2004-2013. PLoS Med. 2019, 16, e1003009. [CrossRef]

16. Hashim, M.; Radwan, H.; Hasan, H.; Obaid, R.S.; Al Ghazal, H.; Al Hilali, M.; Rayess, R.; Chehayber, N.; Mohamed, H.J.J.; Naja, F. Gestational weight gain and gestational diabetes among Emirati and Arab women in the United Arab Emirates: Results from the MISC cohort. BMC Pregnancy Childbirth 2019, 19, 463. [CrossRef]

17. Ancira-Moreno, M.; Vadillo-Ortega, F.; Rivera-Dommarco, J.; Sánchez, B.N.; Pasteris, J.; Batis, C.; Castillo-Castrejón, M.; O'Neill, M.S. Gestational weight gain trajectories over pregnancy and their association with maternal diet quality: Results from the PRINCESA cohort. Nutrition 2019, 65, 158-166. [CrossRef]

18. Macsween, K.; Whelan, E.; Woolcott, C.G. Gestational Weight Gain and Perinatal Outcomes in Adolescent Mothers: A Retrospective Cohort Study. J. Obstet. Gynaecol. Can. 2016, 38, 338-345. [CrossRef]

19. Briggs, M.M.; Hopman, W.M.; Jamieson, M.A. Comparing Pregnancy in Adolescents and Adults: Obstetric Outcomes and Prevalence of Anemia. J. Obstet. Gynaecol. Can. 2007, 29, 546-555. [CrossRef]

20. Lohman, T.J.; Roache, A.F.; Martorell, R. Anthropometric Standardization Reference Manual. Med. Sci. Sports Exerc. 1992, $24,952$. [CrossRef]

21. Onis, M.; Who Multicentre Growth Reference Study Group. WHO Child Growth Standards Based on Length/height, Weight and Age. Acta Paediatr. 2007, 95, 76-85.

22. Committee on Implementation of the IOM Pregnancy Weight Gain Guidelines; Board on Children, Youth, and Families; Food and Nutrition Board; Institute of Medicine. National Research Council Leveraging Action to Support Dissemination of Pregnancy Weight Gain Guidelines: Workshop Summary; National Academies Press: Washington, DC, USA, 2014; ISBN 9780309289665.

23. Goyal, A.; Gupta, Y.; Singla, R.; Kalra, S.; Tandon, N. American Diabetes Association "Standards of Medical Care-2020 for Gestational Diabetes Mellitus": A Critical Appraisal. Diabetes Ther. 2020, 11, 1639-1644. [CrossRef]

24. Visintin, C.; Mugglestone, M.A.; Almerie, M.Q.; Nherera, L.M.; James, D.; Walkinshaw, S. Guideline Development Group Management of Hypertensive Disorders during Pregnancy: Summary of NICE Guidance. BMJ 2010, 341, c2207. [CrossRef]

25. Hypertension in Pregnancy. Report of the American College of Obstetricians and Gynecologists' Task Force on Hypertension in Pregnancy. Obstet. Gynecol. 2013, 122, 1122-1131. [CrossRef] 
26. WHO Haemoglobin Concentrations for the Diagnosis of Anaemia and Assessment of Severity. In Vitamin and Mineral Nutrition Information System; World Health Organization: Geneva, Switzerland, 2011.

27. Flores-Huerta, S.; Klünder-Klünder, M.; Muñoz-Hernández, O. Physical growth and nutritional status of Mexican infants from newborn to two years of age. Salud Publica Mex. 2012, 54, s82-s89. [CrossRef]

28. StataCorp. Stata Statistical Software; StataCorp LLC: College Station, TX, USA, 2019.

29. Zheng, Z.; Bennett, W.L.; Mueller, N.T.; Appel, L.J.; Wang, X. Gestational Weight Gain and Pregnancy Complications in a High-Risk, Racially and Ethnically Diverse Population. J. Womens Health 2019, 28, 375-383. [CrossRef]

30. Groth, S.W.; Holland, M.L.; Smith, J.A.; Meng, Y.; Kitzman, H. Effect of Gestational Weight Gain and Prepregnancy Body Mass Index in Adolescent Mothers on Weight and Body Mass Index of Adolescent Offspring. J. Adolesc. Health 2017, 61, 626-633. [CrossRef]

31. Kac, G.; Arnold, C.D.; Matias, S.L.; Mridha, M.K.; Dewey, K.G. Gestational weight gain and newborn anthropometric outcomes in rural Bangladesh. Matern. Child Nutr. 2019, 15, e12816. [CrossRef]

32. Betran, A.P.; Torloni, M.R.; Zhang, J.; Ye, J.; Mikolajczyk, R.; Deneux-Tharaux, C.; Oladapo, O.T.; Souza, J.P.; Tunçalp, Ö.; Vogel, J.P.; et al. What is the optimal rate of caesarean section at population level? A systematic review of ecologic studies. Reprod. Health 2015, 12,1-10. [CrossRef]

33. Betrán, A.P.; Ye, J.; Moller, A.-B.; Zhang, J.; Gülmezoglu, A.M.; Torloni, M.R. The Increasing Trend in Caesarean Section Rates: Global, Regional and National Estimates: 1990-2014. PLoS ONE 2016, 11, e0148343. [CrossRef]

34. Zhang, F.; Cheng, J.; Yan, S.; Wu, H.; Bai, T. Early Feeding Behaviors and Breastfeeding Outcomes after Cesarean Section. Breastfeed. Med. 2019, 14, 325-333. [CrossRef]

35. Ganchimeg, T.; Ota, E.; Morisaki, N.; Laopaiboon, M.; Lumbiganon, P.; Zhang, J.; Yamdamsuren, B.; Temmerman, M.; Say, L.; Tunçalp, Ö.; et al. Pregnancy and childbirth outcomes among adolescent mothers: A World Health Organization multicountry study. BJOG Int. J. Obstet. Gynaecol. 2014, 121, 40-48. [CrossRef]

36. Stephen, G.; Mgongo, M.; Hashim, T.H.; Katanga, J.; Stray-Pedersen, B.; Msuya, S.E. Anaemia in Pregnancy: Prevalence, Risk Factors, and Adverse Perinatal Outcomes in Northern Tanzania. Anemia 2018, 2018, 1-9. [CrossRef]

37. Khan, U.H.; Asif, E.; Hassan, S.A.; Zohra, R.R.; Hanif, E. Prevalence of Nutritional Anaemia with Association of (BMI) Body Mass Index among Karachi University students, Pakistan. J. Pak. Med. Assoc. 2021, 71, 55-58. [CrossRef]

38. Mocking, M.; Savitri, A.I.; Uiterwaal, C.S.P.M.; Amelia, D.; Antwi, E.; Baharuddin, M.; Grobbee, D.E.; Klipstein-Grobusch, K.; Browne, J.L. Does body mass index early in pregnancy influence the risk of maternal anaemia? An observational study in Indonesian and Ghanaian women. BMC Public Health 2018, 18, 873. [CrossRef] [PubMed]

39. Sosa-Rubi, S.G.; Dainelli, L.; Silva-Zolezzi, I.; Detzel, P.; Sosa, S.E.Y.; Reyes-Muñoz, E.; Chivardi, C.; Panozo, E.O.; Lopez-Ridaura, R. Short-term health and economic burden of gestational diabetes mellitus in Mexico: A modeling study. Diabetes Res. Clin. Pract. 2019, 153, 114-124. [CrossRef] [PubMed]

40. Xie, X.; Liu, J.; Pujol, I.; López, A.; Martínez, M.J.; García-Patterson, A.; Adelantado, J.M.; Ginovart, G.; Corcoy, R. Inadequate Weight Gain According to the Institute of Medicine 2009 Guidelines in Women with Gestational Diabetes: Frequency, Clinical Predictors, and the Association with Pregnancy Outcomes. J. Clin. Med. 2020, 9, 3343. [CrossRef] [PubMed]

41. Stewart, Z.A.; Wallace, E.M.; Allan, C.A. Patterns of weight gain in pregnant women with and without gestational diabetes mellitus: An observational study. Aust. N. Z. J. Obstet. Gynaecol. 2012, 52, 433-439. [CrossRef] [PubMed]

42. Hillier, T.A.; Ogasawara, K.K.; Pedula, K.L.; Vesco, K.K.; Oshiro, C.E.S.; Van Marter, J.L. Timing of Gestational Diabetes Diagnosis by Maternal Obesity Status: Impact on Gestational Weight Gain in a Diverse Population. J. Womens Health 2020, 29, 1068-1076. [CrossRef] [PubMed]

43. Hagiwara, Y.; Kasai, J.; Nakanishi, S.; Saigusa, Y.; Miyagi, E.; Aoki, S. Should the IADPSG criteria be applied when diagnosing early-onset gestational diabetes? Diabetes Res. Clin. Pract. 2018, 140, 154-161. [CrossRef]

44. Berglund, S.K.; García-Valdés, L.; Torres-Espinola, F.J.; Segura, M.T.; Martínez-Zaldívar, C.; Aguilar, M.J.; Agil, A.; Lorente, J.A.; Florido, J.; Padilla, C.; et al. Maternal, fetal and perinatal alterations associated with obesity, overweight and gestational diabetes: An observational cohort study (PREOBE). BMC Public Health 2016, 16, 207. [CrossRef]

45. Barbosa, I.R.C.; Silva, W.B.M.; Cerqueira, G.S.G.; Novo, N.F.; Almeida, F.A.; Novo, J.L.V.G. Maternal and fetal outcome in women with hypertensive disorders of pregnancy: The impact of prenatal care. Ther. Adv. Cardiovasc. Dis. 2015, 9, 140-146. [CrossRef]

46. Amanak, K.; Sevil, U.; Karacam, Z. The Impact of Prenatal Education Based on the Roy Adaptation Model on Gestational Hypertension, Adaptation to Pregnancy and Pregnancy Outcomes. J. Pak. Med. Assoc. 2019, 69, 11-17.

47. Tomimatsu, T.; Mimura, K.; Matsuzaki, S.; Endo, M.; Kumasawa, K.; Kimura, T. Preeclampsia: Maternal Systemic Vascular Disorder Caused by Generalized Endothelial Dysfunction Due to Placental Antiangiogenic Factors. Int. J. Mol. Sci. 2019, 20, 4246. [CrossRef]

48. Dasinger, J.H.; Abais-Battad, J.M.; Mattson, D.L. Influences of environmental factors during preeclampsia. Am. J. Physiol. Integr. Comp. Physiol. 2020, 319, R26-R32. [CrossRef]

49. Lo, J.O.; Mission, J.F.; Caughey, A.B. Hypertensive disease of pregnancy and maternal mortality. Curr. Opin. Obstet. Gynecol. 2013, 25, 124-132. [CrossRef]

50. Young, O.M.; Twedt, R.; Catov, J.M. Pre-pregnancy maternal obesity and the risk of preterm preeclampsia in the American primigravida. Obesity 2016, 24, 1226-1229. [CrossRef] 
51. Spradley, F.T. Metabolic abnormalities and obesity's impact on the risk for developing preeclampsia. Am. J. Physiol. Integr. Comp. Physiol. 2017, 312, R5-R12. [CrossRef]

52. Koenig, M.D.; Klikuszowian, E.; O’Brien, K.O.; Pauls, H.; Steffen, A.; Demartelly, V.; Ruchob, R.; Welke, L.; Hemphill, N.; LaBomascus, B.; et al. Prepregnancy Obesity Is Not Associated with Iron Utilization during the Third Trimester. J. Nutr. 2020, 150, 1397-1404. [CrossRef]

53. Campos, C.A.S.; Malta, M.B.; Neves, P.A.R.; Lourenço, B.H.; Castro, M.C.; Cardoso, M.A. Gestational weight gain, nutritional status and blood pressure in pregnant women. Rev. Saude Publica 2019, 53, 57. [CrossRef]

54. Casanueva, E.; Viteri, F.E.; Mares-Galindo, M.; Meza-Camacho, C.; Loría, A.; Schnaas, L.; Valdés-Ramos, R. Weekly Iron as a Safe Alternative to Daily Supplementation for Nonanemic Pregnant Women. Arch. Med. Res. 2006, 37, 674-682. [CrossRef]

55. Casanueva, E.; Jiménez, J.; Meza-Camacho, C.; Mares, M.; Simon, L. Prevalence of nutritional deficiencies in Mexican adolescent women with early and late prenatal care. Arch. Latinoam. Nutr. 2003, 53, 35-38.

56. Montoya Romero, J.d.J.; Castelazo Morales, E.; Valerio Castro, E.; Velázquez Cornejo, G.; Nava Muñoz, D.A.; Es-cárcega Preciado, J.A.; Montoya Cossío, J.; Pichardo Villalón, G.M.; Maldonado Aragón, A.; Santana García, H.R.; et al. Re-view by expert group in the diagnosis and treatment of anemia in pregnant women. Federación Mexicana de Colegios de Obstetricia y Ginecología. Ginecol. Obstet. Mex. 2012, 80, 563-580.

57. Diario Oficial de la Federación Norma Oficial Mexicana NOM-007-SSA2-2016. Para La Atención de La Mujer Durante el Embarazo, Parto Y Puerperio, Y de La Persona Recién Nacida; Secretaría de Salud: Mexico City, Mexico, 2016.

58. Patel, A.; Prakash, A.A.; Das, P.K.; Gupta, S.; Pusdekar, Y.V.; Hibberd, P.L. Maternal anemia and underweight as determinants of pregnancy outcomes: Cohort study in eastern rural Maharashtra, India. BMJ Open 2018, 8, e021623. [CrossRef]

59. Xie, Y.; Wang, X.; Mu, Y.; Liu, Z.; Wang, Y.; Li, X.; Dai, L.; Li, Q.; Li, M.; Chen, P.; et al. Characteristics and adverse outcomes of Chinese adolescent pregnancies between 2012 and 2019. Sci. Rep. 2021, 11, 1-12. [CrossRef]

60. Ogawa, K.; Matsushima, S.; Urayama, K.Y.; Kikuchi, N.; Nakamura, N.; Tanigaki, S.; Sago, H.; Satoh, S.; Saito, S.; Morisaki, N. Association between adolescent pregnancy and adverse birth outcomes, a multicenter cross sectional Japanese study. Sci. Rep. 2019, 9, 23651. [CrossRef]

61. Zhao, R.; Xu, L.; Wu, M.L.; Huang, S.H.; Cao, X.J. Maternal pre-pregnancy body mass index, gestational weight gain influence birth weight. Women Birth 2018, 31, e20-e25. [CrossRef]

62. Heredia-Pi, I.B.; Servan-Mori, E.; Darney, B.; Reyes-Morales, H.; Lozano, R. Measuring the adequacy of antenatal health care: A national cross-sectional study in Mexico. Bull. World Health Organ. 2016, 94, 452-461. [CrossRef] [PubMed]

63. Merritt, T.A.; Lawrence, R.A.; Naeye, R.L. The Infants of Adolescent Mothers. Pediatr. Ann. 1980, 9, 32-51. [CrossRef]

64. McDonald, S.D.; Han, Z.; Mulla, S.; Beyene, J.; Knowledge Synthesis Group. Overweight and obesity in mothers and risk of preterm birth and low birth weight infants: Systematic review and meta-analyses. BMJ 2010, 341, c3428. [CrossRef] [PubMed]

65. González-Plaza, E.; Bellart, J.; Martínez-Verdú, M.Á.; Arranz, Á.; Luján-Barroso, L.; Seguranyes, G. Pre-pregnancy overweight and obesity prevalence and relation to maternal and perinatal outcomes. Enferm. Clin. 2021. in Press. [CrossRef]

66. Liu, P.; Xu, L.; Wang, Y.; Zhang, Y.; Du, Y.; Sun, Y.; Wang, Z. Association between perinatal outcomes and maternal pre-pregnancy body mass index. Obes. Rev. 2016, 17, 1091-1102. [CrossRef]

67. Goldstein, R.F.; Abell, S.K.; Ranasinha, S.; Misso, M.; Boyle, J.A.; Black, M.H.; Li, N.; Hu, G.; Corrado, F.; Rode, L.; et al Association of Gestational Weight Gain With Maternal and Infant Outcomes: A Systematic Review and Meta-Analysis. JAMA 2017, 317, 2207-2225. [CrossRef]

68. Hua, X.-G.; Jiang, W.; Hu, R.; Hu, C.-Y.; Huang, K.; Li, F.-L.; Zhang, X.-J. Large for gestational age and macrosomia in pregnancies without gestational diabetes mellitus. J. Matern. Fetal. Neonatal Med. 2019, 33, 3549-3558. [CrossRef]

69. Headen, I.; Cohen, A.; Mujahid, M.; Abrams, B. The accuracy of self-reported pregnancy-related weight: A systematic review. Obes. Rev. 2017, 18, 350-369. [CrossRef] 